\title{
Rancang Bangun Aplikasi Informasi Perkuliahan Berbasis Android
}

\author{
Irma Salamah ${ }^{1}$, Lindawati ${ }^{2}$, Herlina Fitri Handayani ${ }^{3}$ \\ 1,2,3Program Studi Teknik Telekomunikasi Politeknik Negeri Sriwijaya \\ 1,2,3 Jl. Srijaya Negara Bukit Besar Palembang Sumatera Selatan \\ 1irma.salamah@yahoo.com, 2lindawati9111@yahoo.com,3herlinafitri16@gmail.com
}

\begin{abstract}
Nowaday, the development of smartphone technology is increasingly popular. Android as one of the operating systems of mobile devices, provides tools and API for Android developers to develop applications. At universities, smartphone use is popular among students. Through smartphones, the use of mobile and web applications is more effective and efficient with the ease of delivery and receipt of information. In this study, the author made a mobile application that contains academic informations that complements the class schedule, the final semester exam schedule, incidental schedules, academic calendar and the latest announcements with push notification as a reminder for students. With this application it is expected that students can access and obtain the latest information anywhere more easily.
\end{abstract}

Keywords: Android, Academic Informations, Push Notification, Smartphone

Saat ini perkembangan teknologi smartphone semakin populer. Android sebagai salah satu sistem operasi perangkat mobile, menyediakan tools dan API bagi para pengembang Android untuk mengembangkan aplikasinya. Di Perguruan Tinggi, penggunaan smartphone populer dikalangan mahasiswa. Melalui smartphone, penggunaan aplikasi mobile dan web lebih efektif dan efisien dengan adanya kemudahan pengiriman dan perolehan informasi. Pada penelitian ini, penulis membangun sebuah aplikasi mobile yang berisi informasi perkuliahan mencakup jadwal kuliah, jadwal ujian akhir semester, jadwal insidental, kalender akademik dan pengumuman terbaru yang dilengkapi push notification sebagai pengingat bagi mahasiswa. Dengan adanya aplikasi ini diharapkan mahasiswa dapat mengakses dan memperoleh informasi terbaru dimana saja dengan lebih mudah.

Kata kunci: Android, Informasi Perkuliahan, Push Notification, Smartphone

\section{PENDAHULUAN}

Saat ini perkembangan teknologi informasi dan komunikasi sangat pesat khususnya pada teknologi smartphone yang semakin populer, menciptakan area aplikasi baru seiring dengan meningkatnya kemampuan dalam hal daya komputasi, sensor dan komunikasi. Android merupakan salah satu sistem operasi yang digunakan pada smartphone[1]. Sebagai salah satu sistem operasi mobile yang sangat populer, Android menyediakan tools dan API bagi para pengembang Android untuk mengembangkan aplikasinya [2].

Pada perguruan tinggi, penggunaan smartphone sangat populer dikalangan mahasiswa. Melalui smartphone, penggunaan aplikasi mobile dan web lebih efektif dan efisien karena adanya kemudahan dalam penyampaian dan pengaksesan informasi. Teknologi push notification digunakan dalam penyampaian informasi secara real-time melalui pesan singkat pada smartphone. Penggunaan teknologi ini sangat tepat karena penerima dapat secara up to date memperoleh semua informasi yang disampaikan [3]. 
Sebagai salah satu perguruan tinggi yang terus mengikuti kemajuan teknologi, Politeknik Negeri Sriwijaya telah menerapkan sistem informasi akademik yang disebut dengan SISAK (Sistem Informasi Akademik). Seperti sistem informasi akademik pada umumnya, SISAK Polsri berisi informasi mahasiswa yang mencakup profil dan informasi mata kuliah, dan fitur presensi dosen oleh mahasiswa. Meskipun demikian, Politeknik Negeri Sriwijaya masih menggunakan sistem konvensional dalam penyebaran informasi seperti informasi jadwal kuliah, jadwal ujian akhir, jadwal sidang maupun pengumuman yang ditempel pada mading jurusan. Sistem ini kurang efisien karena mahasiswa dituntut menghadiri gedung kuliah untuk melihat informasi tersebut secara langsung sehingga mahasiswa tidak mendapatkan informasi secara up to date.

Beberapa Universitas atau Perguruan Tinggi telah menerapkan sistem informasi yang lebih maju. Seperti penelitian sebelumnya yang telah membangun sebuah aplikasi sistem informasi akademik berbasis mobile web dengan beberapa fitur berupa profil akademik serta KRS dan KHS. Namun fitur yang tersedia sangat terbatas, selain itu tidak tersedia notifikasi pada aplikasi yang telah dibangun [4]. Pada Universitas atau Perguruan Tinggi, penggunaan aplikasi mobile pada smartphone sangat berguna bagi mahasiswa sehingga pengaksesan informasi perkuliahan menjadi lebih mudah dan up to date. Selain itu, dengan mengakses informasi perkuliahan secara online diharapkan mampu mengurangi penggunaan kertas (less paper consumption). Berdasarkan permasalahan diatas, penulis melakukan rancang bangun aplikasi informasi perkuliahan berbasis Android yang dilengkapi dengan push notifications.

\section{METODOLOGI PENELITIAN}

\subsection{Metode Pengembangan Perangkat Lunak}

Metode pengembangan perangkat lunak yang digunakan yaitu metode Rational Unified Process (RUP) dengan menggunakan use case driven dan dilakukan secara iteratif[5].

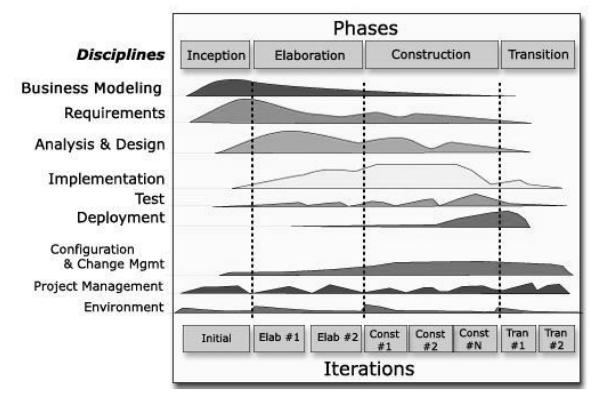

Gambar 1. Arsitektur RUP

Ada 4 tahapan dalam metode RUP ini yaitu sebagai berikut:

a. Inception

Merupakan tahapan awal yang dilakukan dengan menganalisis kebutuhan user dan melakukan perancangan awal aplikasi seperti perancangan diagram use case aplikasi. 


\section{b. Elaboration}

Pada tahap ini dilakukan desain aplikasi, dimulai dari tampilan splash screen, log in serta tampilan menu-menu lainnya yang ada dalam aplikasi.

c. Construction

Pada tahap ini dilakukan konstruksi atau implementasi. Pembangunan aplikasi yang berbasis android dilakukan dengan menggunakan software Android Studio. Pada tahap ini juga dilakukan pengetesan aplikasi untuk mengetahui apakah aplikasi telah sesuai dan berjalan dengan baik.

d. Transition

Instalasi, penyebaran dan sosialisasi kepada mahasiswa.

\subsection{Desain Aplikasi}

Adapun rancangan tampilan aplikasi berbasis Android yang akan dibangun sebagai berikut:

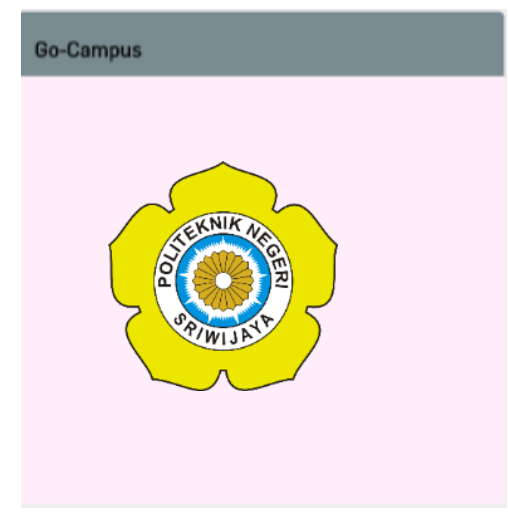

(a) Tampilan Splash Screen

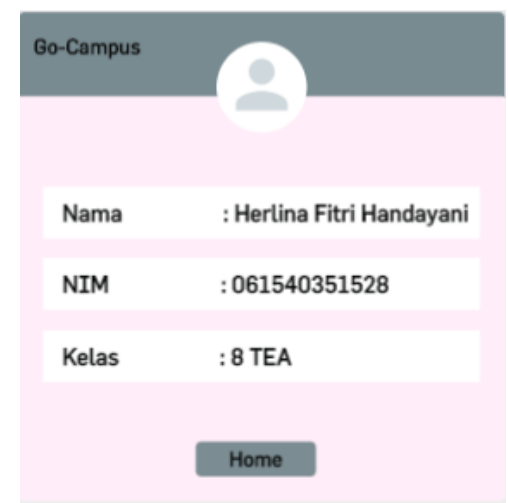

(c) Tampilan Profil Mahasiswa

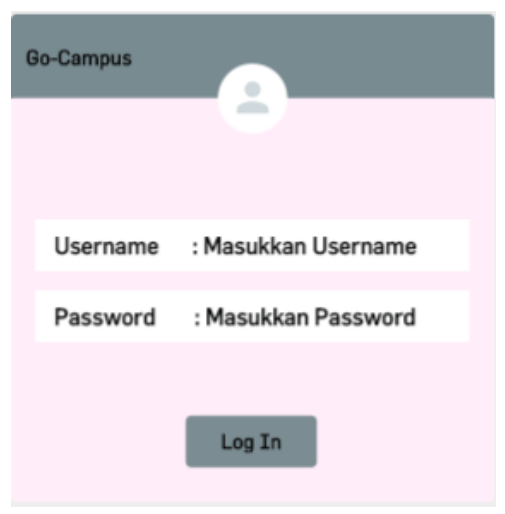

(b) Halaman Log In

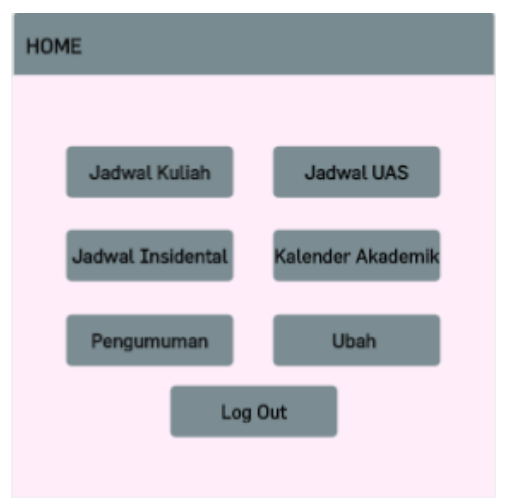

(d) Menu Utama 


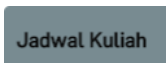

\section{Senin}

Praktek Anntena dan Propagasi

Network Security

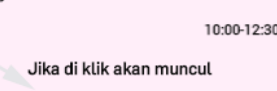

Dosen Pengampu:

Selasa

(e) Tampilan Jadwal Kuliah

\section{Jadwal Insidental}

List Jadwal Insidental

(g) Tampilan Jadwal Insidental

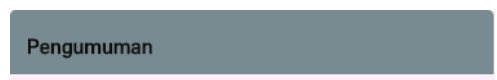

(i) Tampilan Pengumuman

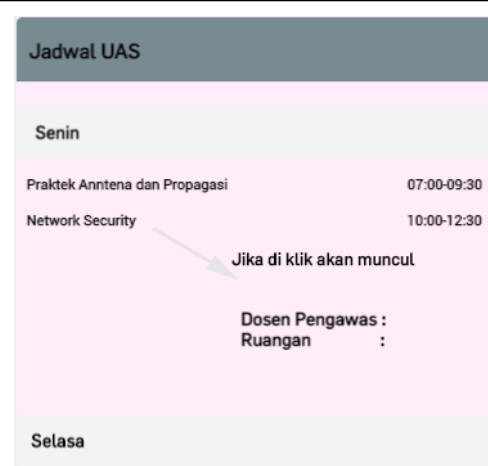

(f) Tampilan Jadwal UAS

\section{Kalender Akademik}

Tampilan Kalender beserta

detail kegiatan akademik

yang ada pada bulan

tersebut.

(h) Tampilan Kalender Akademik
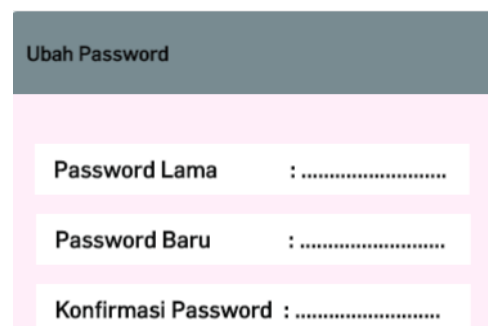

Simpan

(j) Tampilan Ubah Password

Gambar 2. Desain Tampilan Aplikasi

\section{HASIL DAN PEMBAHASAN}

\subsection{Hasil}

Hasil penelitian ini berupa aplikasi Go-Campus yang berisi beberapa menu seperti informasi jadwal kuliah, jadwal ujian akhir semester, jadwal insidental, kalender akademik dan pengumuman terbaru yang dilengkapi dengan push notification sebagai pengingat bagi mahasiswa. Adapun beberapa tampilan dari aplikasi Go-Campus ini sebagai berikut: 
a. Halaman Splash Screen

Halaman ini memuat logo Politeknik Negeri Sriwijaya.

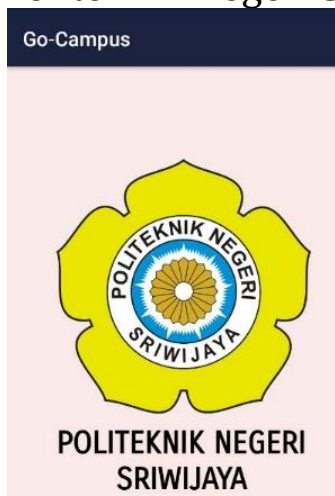

Gambar 3. Tampilan Splash Screen

b. Halaman Log In

Halaman ini berupa format $\log$ in yang harus diisi NIM dan password sesuai dengan data yang diberikan oleh administrasi program studi.

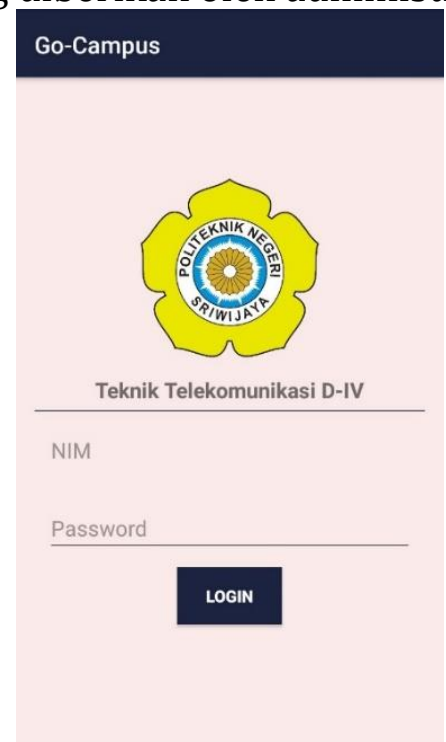

Gambar 4. Tampilan Log In

c. Halaman menu profil mahasiswa

Halaman ini menampilkan data mahasiswa berupa nama, NIM dan kelas dari mahasiswa yang melakukan $\log$ in. 
Jurnal Riset Sistem Informasi Dan Teknik Informatika (JURASIK)

Volume (4) Juli 2019, pp 1-11

ISSN: 2527-5771/EISSN: 2549-7839

http://tunasbangsa.ac.id/ejurnal/index.php/jurasik

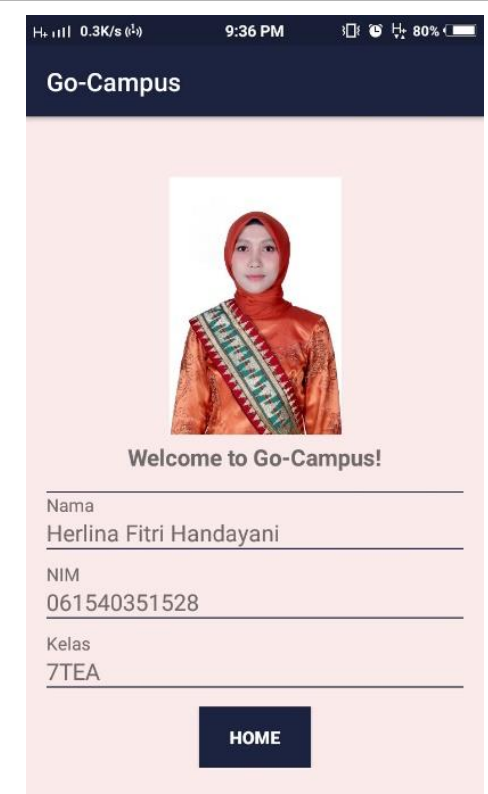

Gambar 5. Tampilan Profil Mahasiswa

d. Halaman menu utama

Halaman ini menampilkan menu utama yang ada pada aplikasi GoCampus.

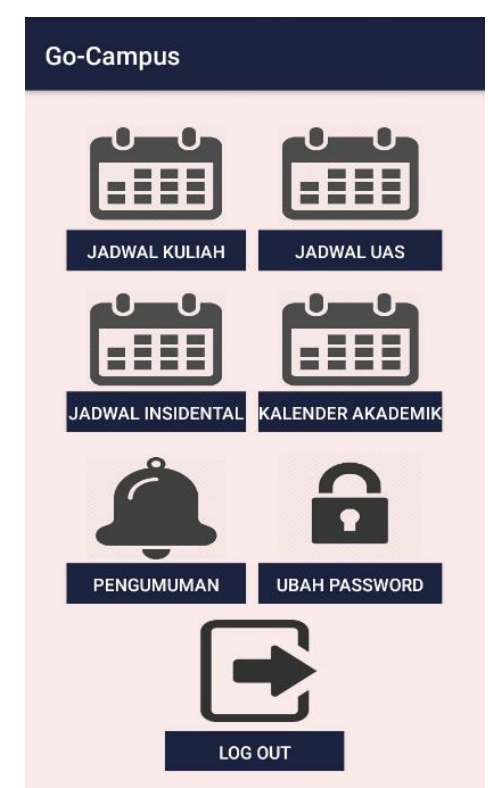

Gambar 6. Tampilan Menu Home

e. Halaman menu jadwal kuliah

Halaman ini menampilkan informasi berupa nama mata kuliah, jam perkuliahan, nama dosen pengampu serta ruangan yang digunakan. 


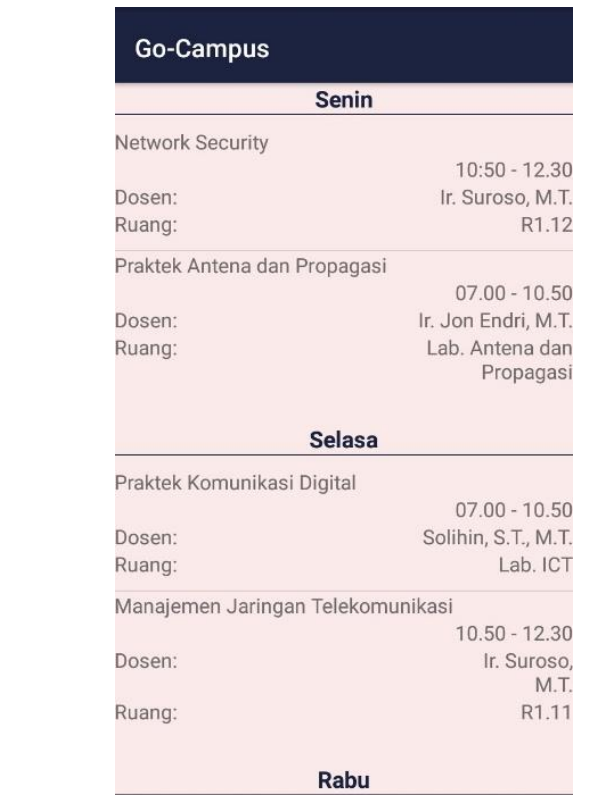

Gambar 7. Tampilan Jadwal Kuliah

f. Halaman menu jadwal ujian akhir semester Halaman ini menampilkan informasi berupa nama mata kuliah yang diujikan, jam ujian, nama dosen pengawas serta ruangan yang digunakan.

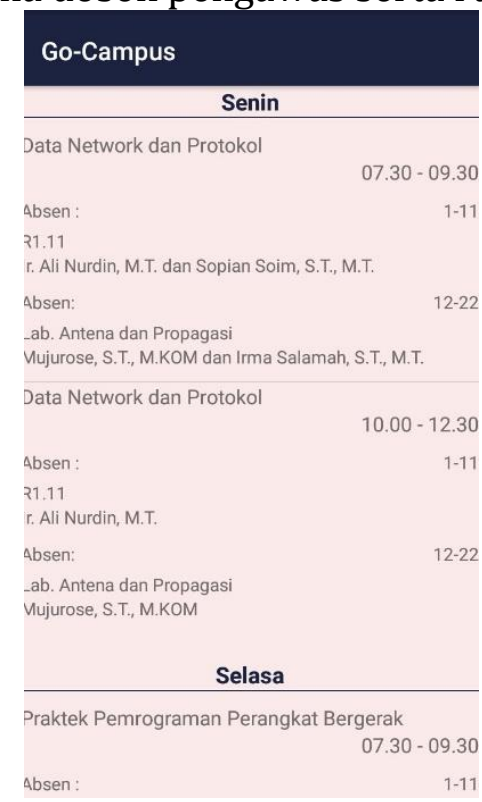

Gambar 8. Tampilan Jadwal Ujian Akhir Semester

g. Halaman menu jadwal insidental

Halaman ini menampilkan informasi nama-nama peserta jadwal insidental yang hanya terjadi pada bulan-bulan tertentu misalnya jadwal seminar proposal pra tugas akhir maupun jadwal sidang kerja praktek (KP). 


\section{Go-Campus \\ LIST JADWAL INSIDENTAL \\ Jadwal Seminar Proposal Pra Tugas Akhir (Pra TA) \\ 2019-02-06 \\ Jadwal Sidang Kerja Praktek (KP) 2019-05-06}

\section{Gambar 9. Tampilan Jadwal Insidental}

h. Halaman menu kalender akademik

Halaman ini menampilkan kalender yang berisi kegiatan akademik yang ada pada bulan yang dipilih.

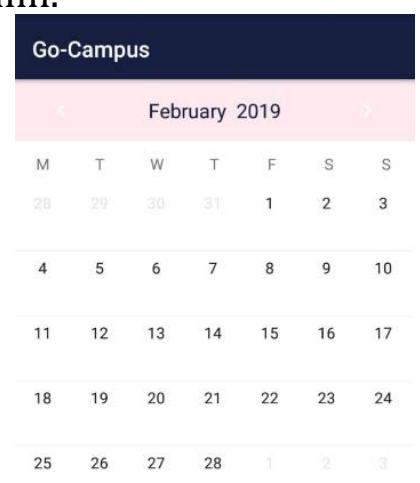

Detail Event

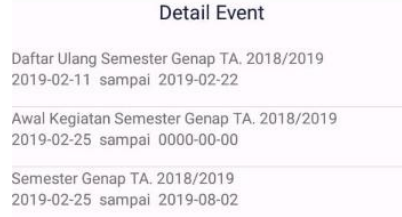

Gambar 10. Tampilan Kalender Akademik

i. Halaman menu pengumuman

Halaman ini menampilkan pengumuman-pengumuman terbaru.

Go-Campus

PENGUMUMAN

Gambar 11. Tampilan Pengumuman

Rancang Bangun Aplikasi Informasi Perkuliahan Berbasis Android (Irma Salamah) |8 
j. Halaman menu ubah password

Halaman ini menampilkan format ubah password. Untuk mengubah password dapat dilakukan dengan mengisi password lama, password baru dan konfirmasi password.

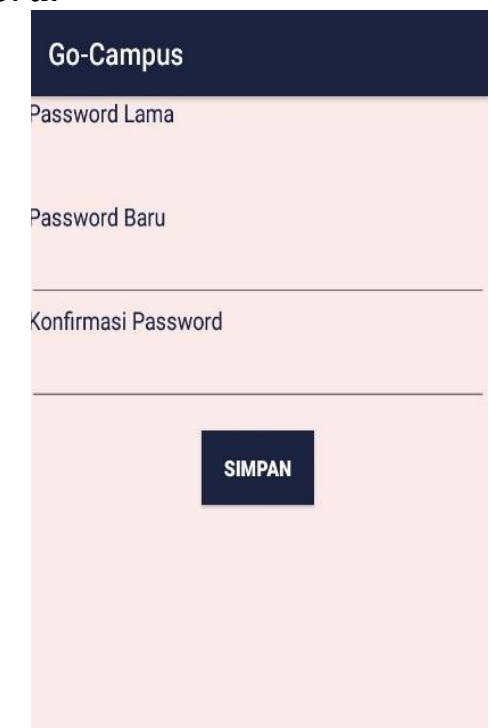

Gambar 12. Tampilan Ubah Password

k. Pemberitahuan melalui push notification

Aplikasi Go-Campus dilengkapi dengan fitur push notification yang akan memberikan pesan singkat pada smartphone mahasiswa setiap ada informasi terbaru yang masuk.

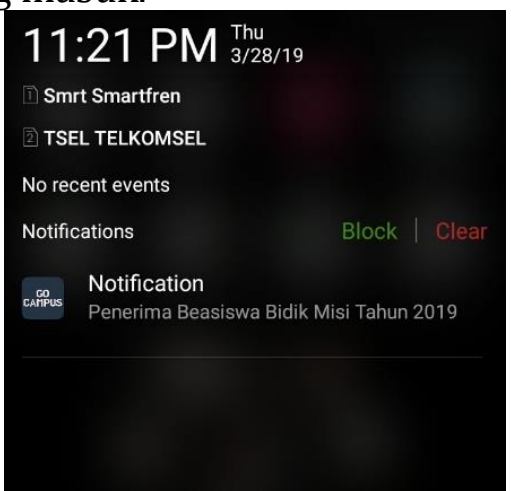

Gambar 13. Tampilan push notification yang masuk

Aplikasi Go-Campus dibangun dengan minimal OS Lollipop 5.0. Pengujian kompatibilitas dilakukan untuk melihat apakah aplikasi mampu berjalan dengan baik pada platform android dengan versi OS diatas atau dibawah OS Lollipop 5.0. Berikut hasil pengujian yang telah dilakukan: 
http://tunasbangsa.ac.id/ejurnal/index.php/jurasik

Tabel 1. Hasil Pengujian Kompatibilitas

\begin{tabular}{|c|c|c|c|}
\hline Merk Perangkat & Tipe & Versi OS & Hasil Eksekusi \\
\hline Vivo Y71 & Smartphone & 8.0 .1 & Berhasil \\
\hline Vivo Y55 & Smartphone & 6.0 .1 & Berhasil \\
\hline Vivo Y51L & Smartphone & 5.0 .1 & Berhasil \\
\hline $\begin{array}{c}\text { Samsung Galaxy } \\
\text { Grand Prime }\end{array}$ & Smartphone & 5.0 .2 & Berhasil \\
\hline $\begin{array}{c}\text { Samsung Galaxy } \\
\text { Mega }\end{array}$ & Smartphone & 4.2 .2 & Gagal \\
\hline
\end{tabular}

\subsection{Pembahasan}

Aplikasi Go-Campus merupakan aplikasi yang memberikan informasi perkuliahan seperti informasi jadwal kuliah, jadwal ujian akhir semester, jadwal insidental, kalender akademik serta pengumuman terbaru yang ada di Politeknik Negeri Sriwijaya khususnya pada Program Studi Teknik Telekomunikasi. Informasi pada menu jadwal kuliah dan jadwal ujian akhir semester yang muncul di setiap akun mahasiswa berbeda berdasarkan kelas atau semester sehingga setiap mahasiswa hanya akan mendapatkan informasi berdasarkan kelasnya. Sedangkan untuk menu yang lain, setiap mahasiswa dapat mengakses dan mendapatkan informasi yang sama. Pada aplikasi Go-Campus ini dilengkapi fitur push notification yang berfungsi sebagai pengingat bagi mahasiswa jika ada informasi terbaru. Hasil pengujian kompatibilitas menunjukkan bahwa penginstalan aplikasi pada Android dengan OS dibawah Android Lollipop 5.0 tidak berhasil. Hal ini karena, pada awal pembuatan aplikasi, OS minimal yang diatur adalah Android Lollipop 5.0. Pada Android dengan OS minimal 5.0 atau diatasnya, aplikasi Go-Campus berjalan dengan baik.

\section{SIMPULAN}

Aplikasi Go-Campus merupakan aplikasi berbasis Android yang memberikan informasi perkuliahan dilengkapi dengan fitur notifikasi sebagai pengingat bagi mahasiswa. Aplikasi ini berguna bagi mahasiswa karena sangat efektif dan efisien dalam pengaksesan infromasi perkuliahan sehingga mahasiswa dapat mendapatkan informasi up to date dimana saja dengan lebih mudah selama terhubung dengan koneksi internet.

\section{UCAPAN TERIMA KASIH}

Penulis ingin mengucapkan terima kasih kepada Heri Sumarsono dan Purwanti selaku orang tua penulis. Irma Salamah, S.T., M.T.I dan Hj. Lindawati, S.T., M.T.I. selaku dosen pembimbing penulis yang telah membantu dalam menyelesaikan paper ini, serta seluruh pihak yang telah turut membantu yang tidak bisa disebutkan satu persatu.

\section{DAFTAR PUSTAKA}

[1] T. Blasing, L. Batyuk, A.-D. Schmidt, S. A. Camtepe, and S. Albayrak, "An Android Application Sandbox system for suspicious software detection," 2010 5th Int. Conf. Malicious Unwanted 
Jurnal Riset Sistem Informasi Dan Teknik Informatika (JURASIK)

Volume (4) Juli 2019, pp 1-11

ISSN: 2527-5771/EISSN: 2549-7839

http://tunasbangsa.ac.id/ejurnal/index.php/jurasik

Softw., pp. 55-62, 2010.

[2] B. Peng, J. Yue, and C. Tianzhou, "The Android Application Development College Challenge," 2012 IEEE 14th Int. Conf. High Perform. Comput. Commun. 2012 IEEE 9th Int. Conf. Embed. Softw. Syst., pp. 1677-1681, 2012.

[3] M. Siddik and A. Nasution, "Perancangan Aplikasi Push Notification Berbasis Android," J. Teknol. dan Sist. Inf., vol. IV, no. 2, pp. 149-154, 2018.

[4] S. Mujab, K. I. Satoto, and K. T. Martono, "Perancangan Sistem Informasi Akademik Berbasis Mobile Web Studi Kasus di Program Studi Sistem Komputer Universitas Diponegoro," pp. 111, 2012.

[5] T. Suryana, "Metode RUP Rational Unified Process," Makal. STMIK LIKMI Bandung, pp. 5-6, 2007. 